\title{
Characteristics of contralateral carcinomas in patients with differentiated thyroid cancer larger than $1 \mathbf{c m}$
}

\author{
Lutske Lodewijk $^{1}$ (1) - Wouter P. Kluijfhout ${ }^{1}$ - Jakob W. Kist ${ }^{1}$ - Inge Stegeman ${ }^{1}$. \\ John T. M. Plukker ${ }^{2}$ • Els J. Nieveen van Dijkum ${ }^{3}$ - H. Jaap Bonjer ${ }^{4}$ Nicole D. Bouvy ${ }^{5}$. \\ Abbey Schepers ${ }^{6}$. Johannes H. W. de Wilt ${ }^{7}$. Romana T. Netea-Maier ${ }^{7}$. Jos A. van \\ der Hage ${ }^{8}$. Jacobus W. A. Burger ${ }^{9}$ Gavin Ho ${ }^{10}$ - Wayne S. Lee ${ }^{10}$ - Wen T. Shen ${ }^{10}$. \\ Anna Aronova $^{11}$ - Rasa Zarnegar ${ }^{11}$ - Cassandre Benay ${ }^{12}$ - Elliot J. Mitmaker ${ }^{12}$. \\ Mark S. Sywak ${ }^{13}$ - Ahmad M. Aniss ${ }^{13}$ - Schelto Kruijff ${ }^{13}$ • Benjamin James ${ }^{14}$. \\ Raymon H. Grogan ${ }^{14}$ • Laurent Brunaud ${ }^{15}$. Guillaume Hoch ${ }^{15}$. Chiara Pandolfi ${ }^{16}$. \\ Daniel T. Ruan ${ }^{16}$ • Michael D. Jones ${ }^{17}$ - Marlon A. Guerrero ${ }^{17}$ • Gerlof D. Valk ${ }^{1}$. \\ Inne H. M. Borel Rinkes ${ }^{1} \cdot$ Menno R. Vriens ${ }^{1,18}$
}

Received: 20 November 2015 / Accepted: 26 February 2016/Published online: 24 March 2016

(C) The Author(s) 2016. This article is published with open access at Springerlink.com

\begin{abstract}
Purpose Traditionally, total thyroidectomy has been advocated for patients with tumors larger than $1 \mathrm{~cm}$. However, according to the ATA and NCCN guidelines (2015, USA), patients with tumors up to $4 \mathrm{~cm}$ are now eligible for lobectomy. A rationale for adhering to total thyroidectomy might be the
\end{abstract}

Lutske Lodewijk and Wouter P. Kluijfhout contributed equally to this work.

Menno R. Vriens

mvriens@umcutrecht.nl

Lutske Lodewijk

L.Lodewijk@umcutrecht.nl

Wouter P. Kluijfhout

Wpkluijfhout@gmail.com

Jakob W. Kist

J.W.Kist@umcutrecht.nl

Inge Stegeman

I.Stegeman@umcutrecht.nl

John T. M. Plukker

j.t.m.plukker@umcg.nl

Els J. Nieveen van Dijkum

e.j.nieveenvandijkum@amc.uva.nl

H. Jaap Bonjer

j.bonjer@vumc.nl

Nicole D. Bouvy

n.bouvy@mumc.nl

Abbey Schepers

a.schepers@lumc.nl presence of contralateral carcinomas. The purpose of this study was to describe the characteristics of contralateral carcinomas in patients with differentiated thyroid cancer (DTC) larger than $1 \mathrm{~cm}$.

Methods A retrospective study was performed including patients from 17 centers in 5 countries. Adults diagnosed with
Johannes H. W. de Wilt

H.deWilt@chir.umcn.nl

Romana T. Netea-Maier

Romana.Netea-Maier@radboudumc.nl

Jos A. van der Hage

j.vd.hage@nki.nl

Jacobus W. A. Burger

j.burger@erasmusmc.nl

Gavin Ho

gh97@georgetown.edu

Wayne S. Lee

Wayne.Lee@ucsfmedctr.org

Wen T. Shen

Wen.Shen@ucsfmedctr.org

Anna Aronova

ana2019@nyp.org

Rasa Zarnegar

raz2002@med.cornell.edu

Cassandre Benay

cassandre.benay@gmail.com 
DTC stage T1b-T3 N0-1a M0 who all underwent a total thyroidectomy were included. The primary endpoint was the presence of a contralateral carcinoma.

Results A total of 1313 patients were included, of whom 426 (32\%) had a contralateral carcinoma. The contralateral carcinomas consisted of 288 (67\%) papillary thyroid carcinomas (PTC), $124(30 \%)$ follicular variant of a papillary thyroid carcinoma (FvPTC), 5 (1\%) follicular thyroid carcinomas (FTC), and 3 (1\%) Hürthle cell carcinomas (HTC). Ipsilateral multifocality was strongly associated with the presence of contralateral carcinomas (OR 2.62). Of all contralateral carcinomas, $82 \%$ were $\leq 10 \mathrm{~mm}$ and of those $99 \%$ were PTC or FvPTC. Even if the primary tumor was a FTC or HTC, the contralateral carcinoma was (Fv)PTC in $92 \%$ of cases. Conclusions This international multicenter study performed on patients with DTC larger than $1 \mathrm{~cm}$ shows that contralateral carcinomas occur in one third of patients and, independently of primary tumor subtype, predominantly consist of microPTC.

Keywords Differentiated thyroid carcinoma $\cdot$ Contralateral carcinoma $\cdot$ Papillary microcarcinoma $\cdot$ Surgical strategy

\section{Introduction}

Differentiated thyroid cancer (DTC) is the most common endocrine malignancy and its incidence is rising. The prognosis is excellent with 10-year survival rates over $90 \%$ irrespective of the stage of disease [1]. Until recently, in western countries, treatment of DTC was similar for all stages of macroDTC (DTC larger than $1 \mathrm{~cm}$ ): total thyroidectomy followed by radioactive iodine ablation (RAI) therapy $[2,3]$. However, in the last decade, single-center studies performed in large-volume centers showed no significant differences in recurrence and survival rates in patients diagnosed with macroDTC, who were either treated with lobectomy or total thyroidectomy [4-7]. This has evoked a new discussion about the optimal extent of surgery, whereby according to the ATA and NCCN guidelines (2015, USA), patients with tumors up to $4 \mathrm{~cm}$ are now eligible for lobectomy $[8,9]$.

Traditional arguments for adhering to total thyroidectomy are the presence of contralateral carcinomas, the ability to perform RAI and the use of thyroglobulin as a follow-up marker. There is, however, increasing support for more selective use of RAI [9-11]. Contralateral carcinomas are reported in up to $44 \%$ of patients with DTC [12]. Supporters of total thyroidectomy argue that contralateral carcinomas could affect disease recurrence and survival [12-15]. Interestingly, these data are mainly based on patients with microDTC (DTC smaller than $1 \mathrm{~cm}$ ) and data on the incidence of contralateral carcinomas in macroDTC is currently scarce [16-21].

We, therefore, aimed to describe the incidence and the characteristics of contralateral carcinomas, and subsequently assess determinants correlating with the presence of contralateral carcinomas in patients with macroDTC.

Marlon A. Guerrero

mguerrero@surgery.arizona.edu

Gerlof D. Valk

G.D.Valk@umcutrecht.nl

Inne H. M. Borel Rinkes

I.H.M.BorelRinkes@umcutrecht.nl

aaniss@med.usyd.edu.au

Schelto Kruijff

kruijffs@gmail.com

Benjamin James

benjamin.james@uchospitals.edu

Raymon H. Grogan

rgrogan@surgery.bsd.uchicago.edu

Laurent Brunaud

1.brunaud@gmail.com

Guillaume Hoch

hoch.guillaume@wanadoo.fr

Chiara Pandolfi

cpandolfi@uchicago.edu

Daniel T. Ruan

druan@partners.org

Michael D. Jones

mdjones1@email.arizona.edu
University Medical Center Utrecht, Heidelberglaan 100, 3584

CX Utrecht, The Netherlands

2 University Medical Center Groningen, Hanzeplein 1, 9700 RB Groningen, The Netherlands

3 Academic Medical Center Amsterdam, Meibergdreef 9, 1105 AZ Amsterdam, The Netherlands

$4 \quad$ VU Medical Center, De Boelelaan 1117, 1081 HZ Amsterdam, The Netherlands

5 Maastricht University Medical Center, P. Debyelaan 25, 6229 HX Maastricht, The Netherlands

6 Leiden University Medical Center, Albinusdreef 2, 2333 ZA Leiden, The Netherlands

7 Radboud University Medical Center, Geert Grooteplein-Zuid 10, 6525 GA Nijmegen, The Netherlands 


\section{Patients and methods}

\section{Patients}

We conducted a descriptive, retrospective, cross-sectional, multicenter study in a total of 17 centers in 5 countries. Patients who underwent a total thyroidectomy for DTC, either in one or two stages, who were operated between January 2000 and December 2012 and aged $\geq 18$ years were included. Indication for a completion thyroidectomy was confirmation of DTC larger than $1 \mathrm{~cm}$ in the histologic examination of the lobectomy specimen.

We specifically selected the patients for whom the discussion about the extent of surgery is most relevant. The TNM stages that were included for the different histological subtypes were based on the currently recruiting study of Mallick et al. [10]. This study investigates whether in a subgroup of low-risk patients ablation can be omitted, without compromising recurrence or survival rates. This concerns patients with a papillary thyroid carcinoma (PTC) including, follicular variant of papillary thyroid carcinoma (FvPTC) with stage pT1bT2-T3, N0-N1a-Nx and patients with a follicular thyroid carcinoma (FTC) or a Hürthle cell carcinoma (HTC) stages pT1b-T2, N0-N1a-Nx. The TNM classification from the 7th edition of the AJCC cancer staging manual was used [22].

In Dutch University Medical Centers, all consecutive patients who were operated between 2000 and 2012 were included since these were only limited numbers. In the high-volume international centers, 150 patients were randomly generated from a list that included all patients that fulfilled inclusion criteria who were operated between 2000 and 2012. Cases were selected by creating a list of numbers generated by randomization software. Pathologic staging was performed according to the AJCC cancer staging manual. In the seven participating Dutch University Medical Centers, data entry was performed by the same researcher (WPK). Outside The Netherlands, data were collected by a local investigator, using a well-defined data entry manual to ensure homogeneous input. The study was approved by the institutional

$8 \quad$ Netherlands Cancer Institute, Plesmanlaan 121 - 123, 1066 CX Amsterdam, The Netherlands

9 Erasmus Medical Center, 's-Gravendijkwal 230, 3015 CE Rotterdam, The Netherlands

10 University of California San Francisco Medical Center, 505 Parnassus Ave, San Francisco, CA 94143, USA

11 Weill Cornell Medical Center, 525 E 68th St, New York, NY 10065, USA

12 McGill University Health Centre, 1650 Cedar Avenue, Montreal, Quebec H3G 1A4, Canada

13 Endocrine Surgery Unit, University of Sydney, Camperdown, NSW 2006, Australia review board of the University Medical Center Utrecht (The Netherlands) and in other centers if required.

\section{Characteristics of contralateral carcinomas}

The following characteristics of the contralateral carcinomas were collected: size, histological subtype, and contralateral multifocality.

\section{Determinants associated with contralateral disease}

After performing a pilot study in 30 patients from the UMC Utrecht and by reviewing the recent literature, 13 determinants were selected [17, 20, 23-25]. Determinants included sex, age at diagnosis, size on ultrasound of primary tumor, Bethesda classification of the primary tumor, postoperative $\mathrm{N}$-stage, size of the contralateral lobe on pathology (PA), size of the primary tumor, histological subtype of the primary tumor, multifocality in the lobe of the primary tumor (ipsilateral multifocality), angioinvasion, capsular invasion (cells invading the capsule of the tumor), extrathyroidal growth, and surgical resection margins of the primary tumor (defined by evaluating resection margins at pathology). Data were collected from chart reviews, cytology reports of fine-needle aspiration (FNA), reports of preoperative ultrasound, and the histology reports.

\section{Statistical analysis}

All continuous variables were tested for linear association with the outcome, and in the case of non-linearity, the variable was categorized in clinically relevant groups [26]. The possible determinants were assessed for patients with and without contralateral carcinoma, and univariate regression analysis and multivariate regression analysis were performed. Variables with a $p$ value $<0.1$ in the univariate regression analysis were selected for multivariate analysis. A $p$ value $<0.05$ was considered statistically significant. All statistical analyses were performed using SPSS version 22 (SPSS Inc., Chicago, IL).

14 The University of Chicago Medical Center, 5841 S Maryland Ave, Chicago, IL 60637, USA

15 Centre Hospitalier Universitaire de Nancy, 29 Avenue du Maréchal de Lattre de Tassigny, 54000 Nancy, France

16 Brigham and Women's Hospital, 75 Francis St, Boston, MA 02115, USA

17 The University of Arizona Medical Center, 3838 N Campbell Ave, Tucson, AZ 85719, USA

18 Department of Surgery (G.04.228), University Medical Center Utrecht, P.O. Box 85500, 3508 GA Utrecht, The Netherlands 


\section{Results}

\section{Patients}

In total, we included 1313 patients in 17 centers (Table 1). The mean age at time of surgery was 47.4 years (SD 14.5), and 967 (74 \%) patients were female. Total thyroidectomy as primary surgical intervention was performed in 961 (73\%) patients, whereas $352(27 \%)$ patients initially had a lobectomy followed by completion thyroidectomy. Central lymph node dissection was not standard of care but was performed dependent of the presence of suspicious lymph nodes on preoperative ultrasound, preference of the surgeon and the clinic. The histological subtype of the primary tumor was PTC in 794 patients (61 \%), FvPTC in 354 (27\%), FTC in $116(9 \%)$, and HTC in 38 (3\%). Unilateral tumor multifocality was seen in 277 (21\%) patients, and 269 (22\%) had central lymph node metastases. Capsular invasion, angioinvasion, and extrathyroidal growth were found in 415 (41\%), 247 (22\%), and $231(19 \%)$ cases, respectively.

\section{Characteristics of contralateral carcinomas}

The overall rate of contralateral carcinomas was $32 \%$ (Table 2). The majority of contralateral carcinomas were PTC $(N=284 ; 69 \%)$ or FvPTC $(N=123 ; 30 \%)$, while only a few were FTC $(N=4 ; 1 \%)$ and HTC $(N=3 ; 1 \%)$ (Table 3$)$. The median size of the contralateral carcinomas was $4 \mathrm{~mm}$

Table 1 Distribution of number of included patients per center

\begin{tabular}{|c|c|c|}
\hline Country & Hospital & $\begin{array}{l}\text { Number of } \\
\text { patients }\end{array}$ \\
\hline \multirow[t]{9}{*}{ The Netherlands } & UMC Utrecht & 40 \\
\hline & UMC Groningen & 50 \\
\hline & Leiden UMC & 50 \\
\hline & Radboud UMC & 31 \\
\hline & Maastricht UMC+ & 15 \\
\hline & Erasmus UMC & 49 \\
\hline & VU Medical Center & 26 \\
\hline & Amsterdam Medical Center & 26 \\
\hline & Antonie van Leeuwenhoek Hospital & 23 \\
\hline \multirow[t]{5}{*}{ USA } & University of California San Francisco & 106 \\
\hline & Weill Cornell Medical College & 106 \\
\hline & University of Chicago & 128 \\
\hline & Brigham and Women's Hospital & 145 \\
\hline & $\begin{array}{l}\text { The University of Arizona Medical } \\
\text { Center }\end{array}$ & 77 \\
\hline Canada & McGill University Health Center & 99 \\
\hline France & $\begin{array}{l}\text { Centre Hospitalier Universitaire } \\
\text { de Nancy }\end{array}$ & 137 \\
\hline Australia & Royal North Shore Hospital & 205 \\
\hline
\end{tabular}

(IQR 2-9 $\mathrm{mm})$. If the primary tumor was non-(Fv)PTC, so FTC or HTC, the contralateral carcinoma was (Fv)PTC in $92 \%$ of the cases. Sixty percent of the contralateral tumors were $5 \mathrm{~mm}$ or smaller, $21 \%$ were between 6 and $10 \mathrm{~mm}$, and $18 \%$ were larger than $10 \mathrm{~mm}$. Of the $82 \%$ of tumors sized $10 \mathrm{~mm}$ or smaller, $99 \%$ were PTC or FvPTC. Six out of the total of eight contralateral FTCs or HTCs were $10 \mathrm{~mm}$ or larger (Table 4).

Ipsilateral multifocality was most frequent when the primary tumor was PTC (23\%), followed by FvPTC (20\%), HTC (18\%), and FTC (9\%). The histological subtype of the ipsilateral tumors was PTC or FvPTC in $99 \%$ of patients (data not shown).

\section{Determinants associated with contralateral disease}

Based on the presence of contralateral carcinomas, univariate analysis of possible determinants was performed (Table 2). Contralateral carcinoma was significantly more frequent in patients with N1a nodal metastasis (OR $1.5695 \%$ CI 1.182.07), in tumors with extra-thyroidal growth (OR $1.5695 \%$ CI 1.16-2.10), and when ipsilateral multifocality was found (OR 2.64 95\% CI 2.01-3.47). When the histologic subtype of the primary tumor was a FTC or a HTC, the likelihood that a contralateral carcinoma was present decreased significantly (FTC: OR $0.3895 \%$ CI 0.23-0.63; HTC: OR $0.3495 \%$ CI $0.14-0.83)$. In multivariate analysis, ipsilateral multifocality (OR 2.62 $95 \%$ CI 1.60-4.29) and lymph node metastasis (OR $1.8995 \%$ CI 1.07-3.34) were strongly correlated with the occurrence of contralateral carcinoma(s). Furthermore, when the primary carcinomas were FvPTC, FTC, or HTC, there was a reversed correlation with the occurrence of contralateral carcinomas (FvPTC: OR $0.5895 \%$ CI 0.35-0.97; FTC: OR $0.5495 \%$ CI 0.22-1.33; HTC: OR $0.1695 \% \mathrm{CI}$ 0.03-0.77). The other investigated determinants, sex, age, size primary tumor (US or PA), angioinvasion, capsular invasion, negative resection margins, and size of the contralateral lobe, did not correlate with the presence of contralateral carcinomas.

\section{Discussion}

In this international multicenter study, the incidence and characteristics of contralateral carcinomas were investigated in a large cohort of patients with primary macroDTC. The rate of contralateral malignancies was $32 \%$, and the dominant histological subtype of the contralateral carcinomas was PTC or FvPTC (94\%). Median size was $4 \mathrm{~mm}$ and $82 \%$ of carcinomas was $<1 \mathrm{~cm}$. No correlation between histological subtype of the primary tumor and the subtype of the contralateral tumor was found. Multifocality in the lobe of the primary tumor had the strongest association with contralateral carcinoma in multivariate analysis with an OR of 2.62 . 
Table 2 Descriptive statistics for the study population

\begin{tabular}{|c|c|c|c|c|c|c|}
\hline Determinants & Number & $\begin{array}{l}\text { Contralateral } \\
\text { carcinoma }+\end{array}$ & $\begin{array}{l}\text { OR }(95 \% \mathrm{CI}) \\
\text { univariate analyses }\end{array}$ & $p$ value & $\begin{array}{l}\text { OR }(95 \% \mathrm{CI}) \\
\text { multivariate analyses }\end{array}$ & $p$ value \\
\hline$N$ & 1313 & $426(32 \%)$ & & & & \\
\hline \multicolumn{7}{|l|}{ Sex } \\
\hline Female & $967(74 \%)$ & $320(75 \%)$ & $0.89(0.69-1.14)$ & 0.40 & & \\
\hline Male & $346(26 \%)$ & $106(25 \%)$ & & & & \\
\hline Age & & & $1.01(1.00-1.02)$ & 0.07 & $1.02(1.01-1.04)$ & 0.01 \\
\hline$\leq 45$ & $579(44 \%)$ & $182(43 \%)$ & & & & \\
\hline$\geq 45$ & $734(56 \%)$ & $244(57 \%)$ & & & & \\
\hline Size primary tumor US (mm) & & & $1.00(1.00-1.01)$ & 0.41 & & \\
\hline$<11$ & $32(3 \%)$ & $13(4 \%)$ & & & & \\
\hline $11-20$ & $384(37 \%)$ & $132(39 \%)$ & & & & \\
\hline $21-30$ & $325(31 \%)$ & $87(25 \%)$ & & & & \\
\hline $31-40$ & $148(14 \%)$ & $49(14 \%)$ & & & & \\
\hline$>40$ & $162(15 \%)$ & $61(18 \%)$ & & & & \\
\hline Missing & 262 & & & & & \\
\hline \multicolumn{7}{|l|}{ FNA (Bethesda) } \\
\hline 1 & $57(5 \%)$ & $15(4 \%)$ & & & & \\
\hline 2 & $91(8 \%)$ & $34(9 \%)$ & $0.61(0.33)$ & 0.11 & $0.58(0.21)$ & 0.30 \\
\hline 3 & $85(8 \%)$ & $25(7 \%)$ & $1.01(0.64)$ & 0.96 & $0.83(0.35)$ & 0.68 \\
\hline 4 & $213(19 \%)$ & $55(15 \%)$ & $0.71(0.43)$ & 0.18 & $0.89(0.37)$ & 0.79 \\
\hline 5 & $205(19 \%)$ & $63(18 \%)$ & $0.59(0.41)$ & 0.00 & $0.68(0.37)$ & 0.22 \\
\hline 6 & $456(41 \%)$ & $169(47 \%)$ & $0.75(0.53)$ & 0.12 & $0.93(0.50)$ & 0.81 \\
\hline Missing & 206 & & & & & \\
\hline \multicolumn{7}{|l|}{ Nodal status } \\
\hline No & $979(78 \%)$ & $397(73 \%)$ & $1.56(1.18-2.07)$ & 0.00 & $1.89(1.07-3.34)$ & 0.03 \\
\hline N1a & $269(22 \%)$ & $109(27 \%)$ & & & & \\
\hline Missing & 65 & & & & & \\
\hline Size primary tumor PA (mm) & & & $1.01(1.00-1.02)$ & 0.07 & $1.02(1.00-1.05)$ & 0.03 \\
\hline $11-20$ & $618(47 \%)$ & $197(46 \%)$ & & & & \\
\hline $21-30$ & $370(28 \%)$ & $115(27 \%)$ & & & & \\
\hline $31-40$ & $163(12 \%)$ & $49(12 \%)$ & & & & \\
\hline$>40$ & $162(12 \%)$ & $65(15 \%)$ & & & & \\
\hline \multicolumn{7}{|l|}{ Angio-invasion } \\
\hline No & $901(78 \%)$ & $298(79 \%)$ & $0.93(0.69-1.26)$ & 0.66 & & \\
\hline Yes & $247(22 \%)$ & $78(21 \%)$ & & & & \\
\hline Missing & 165 & & & & & \\
\hline \multicolumn{7}{|l|}{ Capsular invasion } \\
\hline No & $594(59 \%)$ & $187(60 \%)$ & $0.93(0.71-1.22)$ & 0.59 & & \\
\hline Yes & $415(41 \%)$ & $124(40 \%)$ & & & & \\
\hline Missing & 304 & & & & & \\
\hline \multicolumn{7}{|l|}{ Extra-thyroidal growth } \\
\hline No & $1006(81 \%)$ & $307(77 \%) 94(23 \%)$ & $1.56(1.16-2.10)$ & 0.00 & $1.02(0.53-1.93)$ & 0.96 \\
\hline Yes & $231(19 \%)$ & & & & & \\
\hline Missing & 76 & & & & & \\
\hline \multicolumn{7}{|l|}{ Negative margins } \\
\hline No & $374(29 \%)$ & $121(30 \%)$ & $0.99(0.77-1.28)$ & 0.95 & & \\
\hline Yes & $898(71 \%)$ & $289(70 \%)$ & & & & \\
\hline Missing & 41 & & & & & \\
\hline
\end{tabular}


Table 2 (continued)

\begin{tabular}{|c|c|c|c|c|c|c|}
\hline Determinants & Number & $\begin{array}{l}\text { Contralateral } \\
\text { carcinoma }+\end{array}$ & $\begin{array}{l}\text { OR }(95 \% \mathrm{CI}) \\
\text { univariate analyses }\end{array}$ & $p$ value & $\begin{array}{l}\text { OR }(95 \% \mathrm{CI}) \\
\text { multivariate analyses }\end{array}$ & $p$ value \\
\hline \multicolumn{7}{|l|}{ Multifocality } \\
\hline No & $1033(79 \%)$ & $285(67 \%)$ & $2.64(2.01-3.47)$ & 0.00 & $2.62(1.60-4.29)$ & 0.00 \\
\hline Yes & $277(21 \%)$ & $139(33 \%)$ & & & & \\
\hline Missing & 3 & & & & & \\
\hline \multicolumn{7}{|l|}{ Subtype carcinoma } \\
\hline PTC & $794(61 \%)$ & $280(67 \%)$ & & & & \\
\hline FvPTC & $354(27 \%)$ & $113(27 \%)$ & $0.86(0.66)$ & 0.27 & $0.58(0.35)$ & 0.04 \\
\hline FTC & $116(9 \%)$ & $20(5 \%)$ & $0.38(0.23)$ & 0.00 & $0.54(0.22)$ & 0.18 \\
\hline HTC & $38(3 \%)$ & $6(1 \%)$ & $0.34(0.14)$ & 0.02 & $0.16(0.03)$ & 0.02 \\
\hline Missing & 11 & & & & & \\
\hline Size contralateral lobe (mm) & & & $1.00(1.00-1.00)$ & 0.59 & & \\
\hline$<10$ & $261(24 \%)$ & $68(20 \%)$ & & & & \\
\hline$>10-<15$ & $254(24 \%)$ & $85(25 \%)$ & & & & \\
\hline$>15-<25$ & $262(24 \%)$ & $81(23 \%)$ & & & & \\
\hline$>25$ & $299(28 \%)$ & $113(33 \%)$ & & & & \\
\hline Missing & 237 & & & & & \\
\hline
\end{tabular}

Number $(N)$ of patients with a contralateral carcinoma is shown for each determinant. Odds-Ratios (OR) and $p$ values are shown for the uni- and multivariate analyses

US ultrasonography, FNA fine-needle aspiration, $P A$ pathology

The rate of contralateral carcinomas is in agreement with current literature that reports rates between 17 and $43 \%$. Most of these studies focused on contralateral carcinomas in primary papillary thyroid microcarcinomas (microPTC) $[16,17$, 19-21], or had limited patient numbers, failed to report clear in- and exclusion criteria, or excluded patients with FTC [25, 27-29]. In contrast, our study investigated contralateral carcinoma in a large, well-described, and clinically relevant cohort, in which primary tumors were macroDTC. In our study, the rate of contralateral carcinomas was higher in PTC and FvPTC compared to FTC and HTC, 34 versus $17 \%$. This is in line with a study by Machens et al., who found significantly more tumor multifocality in patients with PTC versus FTC [30].

In our study, $82 \%$ of all contralateral carcinomas were microPTC. Based on several other studies, the clinical relevance of microPTCs can be questioned. In an observational trial performed in Japan, including 1235 patients with primary microPTC, tumor progression of more than $3 \mathrm{~mm}$ was noticed in only $8.0 \%$ of patients, novel nodal metastasis developed in $3.8 \%$, and only $6.8 \%$ developed into clinical disease after 10 years of follow-up. Eventually, only $15 \%$ of patients underwent surgery $[11,31]$. These low progression rates show that these primary microPTCs rarely develop into clinically significant thyroid carcinomas. Our study described contralateral microcarcinomas, while this study addressed primary microPTC, and currently, it is unknown whether the natural course of the primary microPTC differs from those of contralateral microPTC. However, this is indirectly investigated by analyzing recurrence rates in the contralateral lobe in studies where DTC is treated by lobectomy. In a study with up to 20 years of follow-up comparing patients with microPTC treated with lobectomy versus treatment with total thyroidectomy, no difference in overall survival or in recurrence rates
Table 3 Histological subtype of the primary tumors versus the histological subtype of the contralateral tumor. Missing: $n=14(3 \%)$

\begin{tabular}{lllllll}
\hline \multicolumn{7}{c}{ Subtype of primary tumor } \\
\hline $\begin{array}{l}\text { Subtype of } \\
\text { contralateral } \\
\text { tumor }\end{array}$ & PTC & PTC & FvPTC & FTC & HTC & Total \\
& FvPTC & $30(11 \%)$ & $84(76 \%)$ & $6(30 \%)$ & $3(50 \%)$ & $123(30 \%)$ \\
& FTC & $1(0 \%)$ & $25 \%)$ & $1(5 \%)$ & $0(0 \%)$ & $4(1 \%)$ \\
& HTC & $2(1 \%)$ & $0(0 \%)$ & $0(0 \%)$ & $1(17 \%)$ & $3(1 \%)$ \\
& Total & $277(100 \%)$ & $111(100 \%)$ & $20(100 \%)$ & $6(100 \%)$ & $414(100 \%)$ \\
\hline
\end{tabular}


Table 4 Size of the contralateral tumor versus the histological subtype of the contralateral tumors. Missing: $n=34(8 \%)$

\begin{tabular}{llllll}
\hline \multicolumn{5}{c}{ Size of contralateral tumor } \\
\hline Subtype of contralateral tumor & & $\leq 5 \mathrm{~mm}$ & $6-10 \mathrm{~mm}$ & $>10 \mathrm{~mm}$ & Total \\
& PTC & $169(71 \%)$ & $54(64 \%)$ & $45(63 \%)$ & $268(68 \%)$ \\
& FVTC & $68(29 \%)$ & $29(35 \%)$ & $21(29 \%)$ & $118(30 \%)$ \\
& FTC & $0(0 \%)$ & $1(1 \%)$ & $4(6 \%)$ & $5(1 \%)$ \\
& HTC & $1(0 \%)$ & $0(0 \%)$ & $2(3 \%)$ & $3(1 \%)$ \\
& Total & $238(100 \%)$ & $84(100 \%)$ & $72(100 \%)$ & $394(100 \%)$ \\
\hline
\end{tabular}

were found [5]. One might assume that in the remaining thyroid lobe, similar rates of contralateral carcinomas were present as in our population. Furthermore, from autopsy reports, it is known that when thyroid glands are thoroughly examined, malignancy rates of up to $36 \%$ are found which is similar to our contralateral carcinoma rate $[1,32]$. Altogether, the clinical relevance of $82 \%$ of the contralateral carcinomas found in our study is questionable.

Currently, there is no consensus whether multifocal carcinomas arise as a result of true multicentricity or intrathyroidal spread of a primary tumor, as it is underlined by the report of the European Society of Endocrine Surgeons 2013 [33]. In our study, no correlation was found between the histological subtype of the primary tumor and that of the contralateral carcinoma. Moreover, even when the primary tumor was of follicular or Hürthle cell origin, $99 \%$ of the contralateral carcinomas was PTC. This suggests that true multicentricity is more likely than intrathyroidal spread.

Patients with DTC have an excellent 10-year overall survival, but they do suffer from a relatively low quality of life (QoL) in comparison with other cancers, such as breast or colorectal cancer $[34,35]$. This decreased QoL is expressed in several adverse physical, psychological, social, and spiritual challenges [34]. After RAI, patients had significantly more complaints of hypo- or hyperthyroidism, resulting in a decreased QoL[35]. Therefore, one of the factors to improve QoL of macroDTC patients is to pursue normal thyroid hormone homeostasis by performing parenchyma-sparing operations. After thyroid lobectomy, hormone replacement might be necessary in 10 to $50 \%$ of patients; this is highly correlated to the TSH level and presence of microsomal antibodies. In patients with low TSH level $(<2.5 \mathrm{mIU} / \mathrm{L})$ and without microsomal antibodies, the risk to become hormone replacement dependent is only $7 \%$. Furthermore, after lobectomy, patients needed a lower dose of levothyroxine and less adjustment steps to become euthyroid [36-38]. Therefore, QoL might improve by performing a lobectomy instead of total thyroidectomy.

As the discussion continues, we believe treatment of DTC will become more and more a patient-tailored matter, in which the pros and cons of lobectomy or total thyroidectomy must be weighed one by one, based on existing evidence and discussed with the patient. The three main arguments in favor of total thyroidectomy are the ability to perform RAI, the use of thyroglobulin as a follow-up marker, and the high rate of contralateral carcinomas. Arguments in favor of lobectomy are reduced complication risk, especially recurrent laryngeal nerve injury and persisting hypocalcaemia, reduced risk of hypothyroidism, and no risk of complications from RAI. Taken the abovementioned arguments into account, we question whether, in case the ultrasound of the contralateral lobe does not show suspicious lesions, the possible presence of microPTC should be an argument in favor of total thyroidectomy.

\section{Conclusion}

This international multicenter study is the largest study performed on patients with macroDTC and confirms that, in patients with macroDTC, the rate of contralateral carcinomas is $32 \%$. This study shows that these contralateral carcinomas predominantly consist of microPTC.

Authors' contributions Study conception and design were performed by Lutske Lodewijk, Wouter P Kluijfhout, Jakob W Kist, Inge Stegeman, Gerlof D Valk, Inne HM Borel Rinkes, and Menno R Vriens. Acquisition of data was performed by Lutske Lodewijk, Wouter P Kluijfhout, John TM Plukker, Els J Nieveen van Dijkum, H Jaap Bonjer, Nicole D Bouvy, Abbey Schepers, Johannes HW de Wilt, Romana T Netea-Maier, Jos A van der Hage, Jacobus WA Burger, Gavin Ho, Wayne S Lee, Wen T Shen, Anna Aranova, Rasa Zarnegar, Cassandre Benay, Elliot J Mitmaker, Mark S Sywak, Ahmad M Aniss, Schelto Kruijff, Benjamin James, Raymon H Grogan, Laurent Brunaud, Guillame Hoch, Chiara Pandolfi, Daniel T Ruan, Michael D Jones, and Marlon A Guerrero. Analysis and interpretation of data were done by Lutske Lodewijk, Wouter P Kluijfhout, Jakob W Kist, Inge Stegeman, Gerlof D Valk, Inne HM Borel Rinkes, and Menno R Vriens. Drafting of manuscript was performed by Lutske Lodewijk, Wouter P Kluijfhout, Jakob W Kist, Gerlof D Valk, Inne HM Borel Rinkes, and Menno R Vriens. Critical revision of the manuscript was performed by Lutske Lodewijk, Wouter P Kluijfhout, Jakob W Kist, Inge Stegeman, John TM Plukker, Els J Nieveen van Dijkum, H Jaap Bonjer, Nicole D Bouvy, Abbey Schepers, Johannes HW de Wilt, Romana T Netea-Maier, Jos A van der Hage, Jacobus WA Burger, Gavin Ho, Wayne S Lee, Wen T Shen, Anna Aranova, Rasa Zarnegar, Cassandre Benay, Elliot J Mitmaker, Mark S Sywak, Ahmad M Aniss, Schelto Kruijff, Benjamin James, Raymon H Grogan, Laurent Brunaud, Guillame Hoch, Chiara Pandolfi, Daniel T Ruan, Michael D Jones, Marlon A Guerrero, Gerlof D Valk, Inne HM Borel Rinkes, and Menno R Vriens. 


\section{Compliance with ethical standards}

Conflict of interest The authors declare that they have no conflict of interest.

Research involving human participants and/or animals Not applicable

Informed consent Not applicable

Open Access This article is distributed under the terms of the Creative Commons Attribution 4.0 International License (http:// creativecommons.org/licenses/by/4.0/), which permits unrestricted use, distribution, and reproduction in any medium, provided you give appropriate credit to the original author(s) and the source, provide a link to the Creative Commons license, and indicate if changes were made.

\section{References}

1. Davies L, Welch HG (2006) Increasing incidence of thyroid cancer in the United States, 1973-2002. JAMA 295(18):2164-2167

2. Cooper DS, Doherty GM, Haugen BR, Hauger BR, Kloos RT, Lee SL, Mandel SJ, Mazzaferri EL, McIver B, Pacini F, Schlumberger M, Sherman SI, Steward DL, Tuttle RM (2009) Revised American Thyroid Association management guidelines for patients with thyroid nodules and differentiated thyroid cancer. Thyroid : Off J Am Thyroid Assoc 19:1167-1214

3. Bilimoria KY, Bentrem DJ, Ko CY, Stewart AK, Winchester DP, Talamonti MS, Sturgeon C (2007) Extent of surgery affects survival for papillary thyroid cancer. Ann Surg 246(3):375-381, discussion 381-374

4. Nixon IJ, Ganly I, Patel SG, Palmer FL, Whitcher MM, Tuttle RM, Shaha A, Shah JP (2012) Thyroid lobectomy for treatment of well differentiated intrathyroid malignancy. Surgery 151(4):571-579

5. Hay ID, Hutchinson ME, Gonzalez-Losada T, McIver B, Reinalda ME, Grant CS, Thompson GB, Sebo TJ, Goellner JR (2008) Papillary thyroid microcarcinoma: a study of 900 cases observed in a 60-year period. Surgery 144(6):980-987, discussion 987-988

6. Adam MA, Pura J, Gu L, Dinan MA, Tyler DS, Reed SD, Scheri R, Roman SA, Sosa JA (2014) Extent of surgery for papillary thyroid cancer is not associated with survival: an analysis of 61,775 patients. Ann Surg 260(4):601-607

7. Mendelsohn AH, Elashoff DA, Abemayor E, St John MA (2010) Surgery for papillary thyroid carcinoma: is lobectomy enough? Arch Otolaryngol Head Neck Surg 136(11):1055-1061

8. Haddad RL, WM. Ball, DW et al (2015) Thyroid carcinoma. NCCN Guidelines version 12015

9. Haugen BR, Alexander EK, Bible KC, Doherty GM, Mandel SJ, Nikiforov YE, Pacini F, Randolph GW, Sawka AM, Schlumberger M, Schuff KG, Sherman SI, Sosa JA, Steward DL, Tuttle RM, Wartofsky L (2016) 2015 American Thyroid Association management guidelines for adult patients with thyroid nodules and differentiated thyroid cancer: the American Thyroid Association guidelines task force on thyroid nodules and differentiated thyroid cancer. Thyroid 26(1):1-133

10. Mallick U, Harmer C, Hackshaw A, Moss L, Io NTMG (2012) Iodine or Not (IoN) for low-risk differentiated thyroid cancer: the next UK National Cancer Research Network randomised trial following HiLo. Clin Oncol (R Coll Radiol) 24(3):159-161

11. Ito Y, Miyauchi A, Kihara M, Higashiyama T, Kobayashi K, Miya A (2014) Patient age is significantly related to the progression of papillary microcarcinoma of the thyroid under observation. Thyroid 24(1):27-34

12. Pacini F, Elisei R, Capezzone M, Mccoli P, Molinaro E, Basolo F, Agate L, Bottici V, Raffaelli M, Pinchera A (2001) Contralateral papillary thyroid cancer is frequent at completion thyroidectomy with no difference in low- and high-risk patients. Thyroid 11(9): 877-881

13. Pasieka JL, Thompson NW, McLeod MK, Burney RE, Macha M (1992) The incidence of bilateral well-differentiated thyroid cancer found at completion thyroidectomy. World J Surg 16(4):711-716, discussion 716-717

14. Ricci JA, Alfonso AE (2012) Multifocal micropapillary thyroid cancer: a new indication for total thyroidectomy? Am Surg 78(11):1211-1214

15. Lee KJ, Cho YJ, Kim JG, Lee DH (2013) How many contralateral papillary thyroid carcinomas can be missed? World J Surg 37(4): 780-785

16. Connor MP, Wells D, Schmalbach CE (2011) Variables predictive of bilateral occult papillary microcarcinoma following total thyroidectomy. Otolaryngol Head Neck Surg 144(2):210-215

17. Koo BS, Lim HS, Lim YC, Yoon YH, Kim YM, Park YH, Rha KS (2010) Occult contralateral carcinoma in patients with unilateral papillary thyroid microcarcinoma. Ann Surg Oncol 17(4):11011105

18. Pitt SC, Sippel RS, Chen H (2009) Contralateral papillary thyroid cancer: does size matter? Am J Surg 197(3):342-347

19. Vasileiadis I, Karakostas E, Charitoudis G, Stavrianaki A, Kapetanakis S, Kouraklis G, Karatzas T (2012) Papillary thyroid microcarcinoma: clinicopathological characteristics and implications for treatment in 276 patients. Eur J Clin Invest 42(6):657-664

20. Zhou YL, Gao EL, Zhang W, Yang H, Guo GL, Zhang XH, Wang OC (2012) Factors predictive of papillary thyroid micro-carcinoma with bilateral involvement and central lymph node metastasis: a retrospective study. World J Surg Oncol 10:67

21. Zhou YL, Zhang W, Gao EL, Dai XX, Yang H, Zhang XH, Wang OC (2012) Preoperative BRAF mutation is predictive of occult contralateral carcinoma in patients with unilateral papillary thyroid microcarcinoma. Asian Pac J Cancer Prev 13(4):1267-1272

22. Edge SB, Compton CC (2010) The American Joint Committee on Cancer: the 7th edition of the AJCC cancer staging manual and the future of TNM. Ann Surg Oncol 17(6):1471-1474

23. Grigsby PW, Reddy RM, Moley JF, Hall BL (2006) Contralateral papillary thyroid cancer at completion thyroidectomy has no impact on recurrence or survival after radioiodine treatment. Surgery 140(6): 1043-1047, discussion 1047-1049

24. Alzahrani AS, Al Mandil M, Chaudhary MA, Ahmed M, Mohammed GE (2002) Frequency and predictive factors of malignancy in residual thyroid tissue and cervical lymph nodes after partial thyroidectomy for differentiated thyroid cancer. Surgery 131(4):443-449

25. Kim ES, Kim TY, Koh JM, Kim YI, Hong SJ, Kim WB, Shong YK (2004) Completion thyroidectomy in patients with thyroid cancer who initially underwent unilateral operation. Clin Endocrinol (Oxf) 61(1):145-148

26. Moons KG, Kengne AP, Woodward M, Royston P, Vergouwe Y, Altman DG, Grobbee DE (2012) Risk prediction models: I. Development, internal validation, and assessing the incremental value of a new (bio) marker. Heart 98(9):683-690

27. Turanli S, Aslan S, Cetin A (2011) Clinical significance of residual occult malignancy in thyroid carcinoma. Am J Otolaryngol 32(5): 398-401

28. Mazeh H, Samet Y, Hochstein D, Mizrahi I, Ariel I, Eid A, Freund HR (2011) Multifocality in well-differentiated thyroid carcinomas calls for total thyroidectomy. Am J Surg 201(6):770-775 
29. Ibrahim B, Forest VI, Hier M, Mlynarek AM, Caglar D, Payne RJ (2015) Completion thyroidectomy: predicting bilateral disease. J Otolaryngol Head Neck Surg 44(1):23

30. Machens A, Holzhausen HJ, Dralle H (2005) The prognostic value of primary tumor size in papillary and follicular thyroid carcinoma. Cancer 103(11):2269-2273

31. Ito Y, Miyauchi A, Inoue H, Fukushima M, Kihara M, Higashiyama T, Tomoda C, Takamura Y, Kobayashi K, Miya A (2010) An observational trial for papillary thyroid microcarcinoma in Japanese patients. World J Surg 34(1):28-35

32. Harach HR, Franssila KO, Wasenius VM (1985) Occult papillary carcinoma of the thyroid. A "normal" finding in Finland. A systematic autopsy study. Cancer 56(3):531-538

33. Iacobone M, Jansson S, Barczynski M, Goretzki P (2014) Multifocal papillary thyroid carcinoma - a consensus report of the European Society of Endocrine Surgeons (ESES). Langenbecks Arch Surg 399(2):141-154

34. Aschebrook-Kilfoy B, James B, Nagar S, Kaplan S, Seng V, Ahsan H, Angelos P, Kaplan EL, Guerrero MA, Kuo JH, Lee JA,
Mitmaker EJ, Moalem J, Ruan DT, Shen WT, Grogan RH (2015) Risk factors for decreased quality of life in thyroid cancer survivors: initial findings from the North American Thyroid Cancer Survivorship Study. Thyroid 25(12):1313-1321

35. Schultz PN, Stava C, Vassilopoulou-Sellin R (2003) Health profiles and quality of life of 518 survivors of thyroid cancer. Head Neck 25(5):349-356

36. Husson O, Haak HR, Oranje WA, Mols F, Reemst PH, van de PollFranse LV (2011) Health-related quality of life among thyroid cancer survivors: a systematic review. Clin Endocrinol (Oxf) 75(4): $544-554$

37. Lee J, Kim SH, Tan AH, Kim HK, Jang HW, Hur KY, Kim JH, Kim KW, Chung JH, Kim SW (2010) Decreased health-related quality of life in disease-free survivors of differentiated thyroid cancer in Korea. Health Qual Life Outcomes 8:101

38. Husson O, Nieuwlaat WA, Oranje WA, Haak HR, van de PollFranse LV, Mols F (2013) Fatigue among short- and long-term thyroid cancer survivors: results from the population-based PROFILES registry. Thyroid 23(10):1247-1255 